\section{In Response to "Matching 25\% of Medical Students Into Family Medicine by 2030: Realistic or Beyond Our Reach?"}

\section{TO THE EDITOR:}

We were pleased to see the recent article "Matching 25\% of Medical Students into Family Medicine by 2030: Realistic or Beyond Our Reach?"' We think this goal is realistic. If we want to make the 25 by 2030 a reality, it is important for medical schools to examine their application and acceptance processes.

The University of Washington School of Medicine (UWSOM) Targeted Rural and Underserved Track (TRUST) program has a separate admissions process from the rest of UWSOM. TRUST graduates match into family medicine (FM) at a rate of $25 \%{ }^{2}$ We further found that students who applied to and participated in the program, as well as students who applied to and were not accepted into the program all matched in FM at the same rate. Implementing a selection process for students who have rural ties, have a stated interest in $\mathrm{FM},{ }^{3}$ and who state they do not have an interest in specialty or academic medicine could go a long way to meeting the $25 \times 2030$ goal.

We acknowledge the challenges identified by Dr David et al. Health care coverage, physician payment, and the overall health system is often misaligned with the core values of FM. We can, however, admit applicants with strong stated interest in FM and rural ties and support their interests during medical school with creative curricula and top-notch faculty and staff to achieve the $25 \times 2030$ goal. The health care system needs improvement, but so do medical school admissions processes. Medical schools can take action today to meet the health care needs of the public. doi: 10.22454/FamMed.2021.721513

Kim Kardonsky, MD

Amanda Kost, MD, MEd

David V. Evans, MD

University of Washington Department of Family Medicine Seattle, WA

\section{References}

1. David AK. Matching $25 \%$ of medical students in family medicine by 2030: realistic or beyond our reach? Fam Med. 2021;53(4):252-255. doi:10.22454/FamMed.2021.982403

2. Kardonsky K, Evans DV, Erickson J, Kost A. Impact of a targeted rural and underserved track on medical student match into family medicine and other needed workforce specialties. Fam Med. 2021;53(2):111-117. doi:10.22454/ FamMed.2021.351484

3. Kost A, Cantone RE, Schneider B, Sairenji T, Palmer R. Validation and comparison of a brief instrument vs a single-item screen to predict entry to family medicine at matriculation to Medical school. Fam Med. 2018;50(9):672-678. doi:10.22454/ FamMed.2018.258795

\section{Author's Response to Drs Kardonsky, Kost, and Evans}

\section{TO THE EDITOR:}

Drs Kardonsky, Kost, and Evans' review, comments, and disagreement with my thesis that " $25 \times 30$ " is unrealistic, is greatly appreciated. Their description of the Tageted Rural Underserved Program (TRUST) at the University of Washington School of Medicine (UWSOM) is outstanding, and is a model for other schools to follow. The outcomes of those students who applied but were not accepted into the TRUST program is also noteworthy and remarkable. The UWSOM has a long history of making family medicine a priority, with a strong family medicine department, and especially with its Wyoming, Alaska, Montana and Idaho (WAMI) collaborative program accepting students from those largely-rural states because they do not have a medical school of their own. This creates a unique pool of applicants, largely rural in background, which is difficult to recreate in the same volumes elsewhere. Overall, UWSOM does well, as noted in the authors' article in the February 2021 issue of Family Medicine, with an overall FM match rate of $16.9 \%$, and a TRUST match rate of $29.1 \%$, averaged from 2013-2018 and compared to a national average of $8.7 \% .^{1}$ These numbers highlight how successful this program has been, and can act as a benchmark for others to follow.

However, the national data set shows little progress, with 1,606 US MD seniors matching in family medicine, compared to the entire pool of 18,435 US MD seniors who matched to a 
postgraduate year-1 position, for a FM match rate of $8.7 \% .^{2}$ Comparing this to the 2020 rate of $8.5 \%$ and the rate in their article of $8.7 \%$, there is essentially no growth. Unfortunately, most medical schools do not have such a large, four-state, rural applicant pool. Instead, their applicants come from largely urban/suburban backgrounds, have never seen a family physician, and have strong specialty interests upon matriculation. Additionally, many deans are evaluated by their schools' rank in terms of National Institutes of Health funding, and not by the percentage of students entering family medicine. Several years ago I listened to a dean from a prestigious research-oriented school who was also the CEO of his health system make the following statement:

No medical student should go into primary care - patients should be seen for primary care needs by nurse practitioners/physician assistants, and then referred to specialists for definitive care.

It seems a bit harsh and is the polar opposite of the work at UWSOM, but it demonstrates the range of medical school priorities.

Lastly, Drs Magill and Saultz pointed out in an editorial titled "Quality Before Quantity" in the same issue as the " $25 \times 30$ " article that there is an integrity issue in family medicine, a disconnect between values and actions. ${ }^{3} \mathrm{We}$ teach that family medicine is a comprehensive specialty providing care for all, across many domains, yet fewer and fewer family physicians provide full-scope care eliminating pediatrics, obstetrics, and hospital care. The exception is rural family medicine. It may be hard to identify with a specialty that preaches comprehensive full-scope care, but whose practitioners in the field are overwhelmed and doing only ambulatory care. It would be interesting to compare attitudes and match rates of UWSOM students going into family medicine based on whether they rotated through a suburban ambulatory-only versuss a full-scope family medicine rural practice.

I believe we are all trying to address the same issue: primary care, especially family medicine, is extremely important to the health and well-being of people in the United States, and we need to motivate and move more medical schools to address this issue. I am philosophically in agreement with Drs Kardonsky, Kost and Evans. We do need a balance of quality and quantity. To achieve this on a national level will require cataclysmic change that is currently not visible on the radar screen. Thus, my sense of reality remains pessimistic.

It would be helpful for the UWSOM faculty to continue these innovative programs and publish their results.

doi: 10.22454/FamMed.2021.911383

Alan K. David, MD

Medical College of Wisconsin - Family Medicine Milwaukee, WI

\section{References}

1. Kardonsky K, Evans DV, Erickson J, Kost A. Impact of a targeted rural and underserved track on medical student match into family medicine and other needed workforce specialties. Fam Med. 2021;53(2):111-117. doi:10.22454/ FamMed.2021.351484

2. National Resident Matching Program. Accessed June 10, 2021. www.nrmp.org

3. Magill MK, Saultz J. Quality before quantity. Fam Med. 2021;53(4):249-251. doi:10.22454/FamMed.2021.156395 